\title{
POSTTRAUMATIC STRESS REACTIONS IN CHILDREN AND ADOLESCENTS ONE YEAR AFTER THE 1999 TAIWAN CHI-CHI EARTHQUAKE
}

\author{
Sue-Huei Chen ${ }^{1}$, Yi-Hui Lin ${ }^{1}$, Hsu-Min Tseng ${ }^{2}$, and Yin-Chang $\mathrm{Wu}^{1 *}$ \\ ${ }^{1}$ Department of Psychology \\ National Taiwan University \\ Taipei, Taiwan 106, R.O.C. \\ ${ }^{2}$ Department of Healthcare Management \\ Chang Gung University \\ Taoyuan, Taiwan 333, R.O.C.
}

Key Words: posttraumatic stress reaction, Chi-Chi Earthquake, exposure effect, children and adolescents.

\begin{abstract}
This study was to investigate the range and severity of post-traumatic stress reactions displayed by children and adolescents residing near the epicenter, one year after the Taiwan Chi-Chi Earthquake and to examine the relations of these symptoms to developmental stages and objective features of trauma exposure. Earthquake Exposure Index for Youths and Child Posttraumatic Stress Disorder Reaction Index were administered to 1,169 children and 1,201 adolescents from two heavily impacted townships. Severity of posttraumatic stress reactions was found to vary by a "dose effect" of earthquake exposure. Variation in the prevalence of PTSD symptoms was found across age and gender groups. Younger children and females reported more PTSD symptoms. More adolescents disclosed restricted negative affects and guilty feelings, whereas younger boys presented such symptoms in a more extreme way. Given that age and gender show variable effects on post-traumatic symptoms developed, there may be a need to implement a broad disaster recovery project with periodic screenings as well as age-specific and gender-appropriate mental health program.
\end{abstract}

\section{INTRODUCTION}

The 1999 Taiwan Chi-Chi Earthquake, which measured 7.3 on the Richter scale, was the most deadly natural disaster in Taiwan in the last century. This devastating earthquake struck the whole island country at near midnight of September 21, 1999 for almost one minute, and especially hit both densely populated farms and the rugged rural mountain regions of central Taiwan, leaving a surprisingly high toll of deaths, injuries, and damage. Approximately 2,494 people lost their lives and over eleven thousand got injured. More than 106,159 houses and a great number of schools were either completely destroyed or damaged (National Alliance for PostEarthquake Reconstruction, 2000). Particularly distressed by the trauma were the children and adolescents of these regions. They have not only been stunned by the fateful events such as personal and/or family injury, witnessing death of family, friends, and

*Correspondence addressee 
neighbors, as well as damages and collapses of houses, but have also been experiencing unfortunate adversities following the earthquake such as being "school-less" due to collapse of their schools, relocation and/or separation from family, and undesirable living conditions.

Exposure to trauma has been a risk factor in psycho-pathogenic impact noted in human history and literature for years. In the Word Disaster Report 1993, the International Federation of the Red Cross and the Red Crescent Societies (IFRC, 1993) pointed out that 7766 disasters worldwide were reported between 1967-1991, with a higher than 7 million death toll and nearly 3 billion affected people. On the other hand, studies have suggested that more than $10 \%$ of people have been exposed to some type of natural disaster in life (Kessler, et al., 1995; Norris, 1992). Thus, disaster is not an uncommon event in the lives of individuals. Although not all cases have devastating consequences, severe traumas may have impacts, physiological and/or psychological, on individuals' lives. Especially, Posttraumatic Stress Disorder (PTSD), as one of the most costly consequences, influences not only the individual's life but also the mental health system and society as well. However, only in the last two decades have researchers started making systematic efforts to investigate PTSD and its correlates. PTSD was first included as an official diagnostic category for adults in the third edition of Diagnostic and Statistical Manual of Mental Disorders (DSM-III) in 1980 (American Psychiatric Association [APA], 1980).

Although children and adolescents are not excluded in disaster encounters, research on children's and adolescents' traumatic responses is even less abundant and less systematic than research on adult trauma. Based on review of previous studies, Orlee (1993) pointed out that, studies prior to 1985 considered disasters to have only short-term effects on children and few empirical studies on trauma-related psychological problems had been conducted with younger subjects. Only in 1987 did a revision of DSM-III (DSM-III-R) finally include an official diagnostic category for children and adolescents (APA, 1987). More and more studies about reactions of children and adolescents following trauma have been carried out in the past two decades and have resulted in mixed findings.

Nevertheless, it has been documented, to date, that children and adolescents may experience the full range of posttraumatic stress symptoms (La Greca $e t$ al., 1996; Pynoos et al., 1993). Once the diagnosis is established in childhood and adolescence, PTSD is usually chronic and debilitating (Green et al., 1994; Nader et al., 1990). The level of exposure appears to be strongly associated with severity and course of posttraumatic stress reactions (Green, 1991; Lonigan et al., 1994; Pynoos et al., 1996). Also, age and gender may present variable effects on risk for PTSD symptoms (Green et al., 1991; Korol et al., 1999; Shaw et al., 1996).

\section{Posttraumatic Stress Reactions in Children and Adolescents}

What may be the commonly seen chronic posttraumatic stress reactions in children? Bradburn (1991) found that, for example, 6-8 months after the San Francisco Earthquake, the most frequently reported symptoms in children of 10-12 years old include recollection of the earthquake caused by reminders $(73 \%)$, feeling fearful while recollecting the event (70\%), exaggerated startle responses (64\%), and intrusive thoughts $(50 \%)$. In a study conducted two years after the Buffalo Creek flooding disaster, Green, et al. (1991) found that the most frequently reported symptoms in children of 2-15 years old include painful feelings caused by reminders $(65 \%)$, diminished social activities (40\%), and restricted affects (39\%). Orlee (1993) concluded that, similar to adults' PTSD, the common posttraumatic reactions to disaster in western children and adolescents include sleep problems such as insomnia, nightmares, fear of being alone in the dark and sleeping alone, and sleepwalking; loss of capacity to learn, impaired concentration, and memory impairment; intrusive images and thoughts triggered by trauma-related environment and often associated with intense anxiety; repeating trauma-related play and games; panic attacks; fear of trauma reminders; separation anxiety; hypervigilance to dangers; decreased self-efficacy and sense of insecurity; loss of derived pleasure from regular activities; anger, irritability, and aggressive behaviors; and depression, guilt and hopelessness.

The profiles of symptom presentation appeared somewhat different in Taiwanese youths during a short period after the Earthquake. For instance, Soong et al. (2000) by using an aboriginal tool, Postearthquake Questionnaire for Students (PEQS), in a survey conducted three months after the Chi-Chi Earthquake found that reexperiencing feeling $(48.6 \%)$, avoiding thoughts $(42.5 \%)$, reliving acts $(41.6 \%)$, and fear of being alone $(41.3 \%)$ are most often reported symptoms in 2-9 graders from a town (Yu-Chih) near the epicenter. Similarly, Chao and Wu (2000), using the same PEQS, found that, approximately 4 months after the same earthquake, behavioral reenactment $(59.2 \%)$, avoidance of thoughts/feelings $(54.9 \%)$, and separation anxiety $(53.9 \%)$ led the PTSD symptom list in 3-6 graders from another town (Tung-Hsih). Distinct from the symptom manifestations in younger children, Hsu 
(2000), by using the Posttraumatic Stress Reaction Index (PTSRI; Chen et al., 2000), in 681 students from a senior high school located near the epicenter ( $\mathrm{Pu}-\mathrm{Li}$ Town), found that difficulty concentrating $(52.8 \%)$, hypervigilance and oversensi-tivity to surroundings $(37.7 \%)$, preoccupation with earthquake reoccurrence $(31.7 \%)$, and hypersomnia $(34.1 \%)$ were the most often reported symptoms three to four months after the Earthquake. These existing studies of Taiwanese youths were all conducted around three to four months after the earthquake. Unanswered is the question whether or not the symptom manifestations and differences between children and adolescents remain over a long period of time.

\section{Predictors of PTSD Symptoms: Trauma Exposure, Age, and Gender}

\section{(i) Trauma Exposure and PTSD Symptoms}

Existing research suggests that individuals more exposed to trauma exhibit a greater extent of posttraumatic stress symptoms in Western samples (Belter et al., 1991; Lonigan et al., 1994; McFarlane, 1987; Shore et al., 1986; Pynoos et al., 1996). For example, Shore et al. (1986) found that higher onset rates of PTSD and other psychiatric disorders were detected in the sample with more exposure to the volcanic eruption of Mount St. Helens during a short period and in the first year after the disaster. Similar patterns were found in adults (Chen et al., 2002) and in Children (Chao \& Wu, 2000) approximately three to four months after the Chi-Chi Earthquake. For example, Chen et al. (2002) found that, compared to low-exposure adults from a rural area of Taipei, highexposure adults living near the epicenter manifested significantly more immediate and delayed posttraumatic psychological responses. Chao and $\mathrm{Wu}$ (2000) reported that children with any kind of earthquake exposure such as being trapped, having injuries to self or relatives, and seeing death scored significantly higher than non-exposed students on PEQS. Although the "dose effect" has been supported by the studies conducted a short period of time after the Chi-Chi Earthquake, in that exposure amount appears to be predictive to posttraumatic stress reactions, McFarlane (1987) pointed out that most highly-exposed survivors recovered as time passed, and that the exposure amount may not account for chronic posttraumatic stress reactions. Thus, a lasting effect of exposure level on chronic PTSD symptoms is yet to be examined in our samples.

\section{(ii) Age and Posttraumatic Stress Reactions}

Existing literature is not yet conclusive about the age effect on the vulnerability of children and adolescents following a traumatic event. Some researchers proposed that the cognitive immaturity of children and adolescents might shield and protect them from the psychological hurts of traumatic events because they lack capacity to grasp the dangers (Blom, 1984). However, others have recently speculated that younger children are at higher risk because of lacking defenses and resources to cope with the threat and loss (Shannon et al., 1994). It is thus interesting to examine whether there also exists an agespecific risk for chronic posttraumatic reactions in Taiwanese youths.

\section{(iii) Gender and Posttraumatic Stress Reactions}

Will gender be a predictor of one's reactions to trauma? Many studies have investigated gender differences of posttraumatic reactions in children and adolescents and girls report more PTSD symptoms and present higher rates of DSM diagnoses in general (Green et al., 1991; Pynoos et al., 1993; Shannon et al., 1994). More specifically, gender differences can be found in symptom manifestation and duration. For example, girls tend to have more chronic PTSD symptoms such as hypervigilance and startle reactions, emotional numbness, somatic complaints, and trauma-related thoughts, while boys display more social withdrawal, anxiety/depression, sleep problems, attention deficits, and conduct problems (Blom, 1984; Shannon et al., 1994; Shaw et al., 1996). Gender differences have been documented in short-term PTSD symptoms in children (Chao and Wu, 2000; Cheng et al., 2000) and high school students (Cheng et al., 2000; Hsu, 2000). Unanswered is whether there also exist gender-specific chronic posttraumatic reactions in Taiwanese youths.

\section{Aims of the Study}

Given that much of the research into trauma and its long-term consequences in children and adolescents has been undertaken among Western samples, the application of existing data to our Taiwanese youths after the Chi-Chi Earthquake is limited. Most local studies with children and adolescents reported short-term PTSD symptoms. Lacking previous research on chronic post-disaster psychological reactions of youths in Taiwan constitutes a prime motive for the current study. In this paper, the authors primarily present a large-scale investigation, conducted one year after the 1999 Chi-Chi Earthquake, that inspects the range and severity of chronic posttraumatic stress reactions displayed by children and adolescents residing near the epicenter so as to plausibly give a database for future research along these 
lines in Taiwan. The study also examines the relations of these symptoms to developmental stages and objective features of trauma exposure in enhancing our current understanding of indigenous post-traumatic reactions in children and adolescents.

\section{METHOD}

\section{Subjects}

The tragedy in Taichung County and Nantou County of Central Taiwan represented at least $80 \%$ of the total death, injury, and damage toll in Taiwan, after the Chi-Chi Earthquake. Tung-Hsih Town of Tai-Chung County and Pu-Li Town of Nan-Tou County, located within the perimeter of the Earthquake epicenter, had the highest death, injury, and damage tolls in the whole country. Most survivors from these two towns have been relocated to other cities or placed in temporary residences including prefab housing, container homes, or sheet-metal shelters after the earthquake. As of when data collection for this study was undertaken during the first two weeks of September 2000, there were still a great number of survivors living in container homes.

Subjects for this study, from fourth- through ninth- graders, came from four public elementary and four junior high schools, two of each located in TungHsih Town and also in Pu-Li Town. Study schools were selected on the basis of location and degree of damage. Half of the schools, at each level, in each town, collapsed and their students were relocated in temporary container classrooms, and the other half remained unmoved. Students from these schools were recruited as they were adequately representative of the population in these two areas. Once the unusable subjects were eliminated, 1,169 elementary and 1,201 junior high students (aged 11.26 \pm 0.96 years and $13.96 \pm 0.97$, respectively) made up the final sample, consisting of $52.4 \%$ males $(N=1241)$ and $47.6 \%$ females $(N=1129)$ as can be seen in Table 1. Parallel to the towns' ethnic makeup, the majority students in the Tung-Hsih sample and the Pu-Li sample are Hakka Taiwanese $(82.6 \%)$ and Horlor Taiwanese $(73.1 \%)$, respectively. Otherwise, there exist no gender or age effects on student numbers from each age group.

\section{Measures}

(i) Earthquake Exposure Index for Youths

The self-report 10-item Earthquake Exposure Index for Youths (EEIY) was modified from the Earthquake Exposure Index (Chen et al., 2000; Chen et al., 2002) with additional youth-relevant items to assess the extent of exposure to the earthquake. It consists of 1) index for death and injury, including physical injury level in self, injury and/or death in family member(s) and relatives, and injury and/or death in friends; 2) index for property loss, i.e., degree of house damage; and 3 ) index for life destruction, including current dwellings and separation from parents.

(ii) UCLA PTSD Index for DSM-IV, Revision 1, Adolescent version

The self-report UCLA PTSD Index for DSMIV, Revision 1, Adolescent Version (Pynoos, et al., 1996), through forward-backward translation procedures, was adapted to evaluate the incidence of past trauma experiences (i.e., the 13-item Past Trauma Experience Survey; PTES) and posttraumatic stress symptoms (i.e., the 20-item Checklist of PTSD Symptoms; CPTSD). Incidence of past trauma experiences was rated as $0-N O$ or 1-YES, including earthquake, traffic accidents, war, fighting, gun-shot, and so on. Frequency of occurrence of symptoms was rated on a 5-point Likert scale ranging from 0-None to 4-Most of the time. As the tool was first used in Taiwan, the authors conducted psychometric examinations of the scale and reported elsewhere (Lin, 2001; Wu et al., 2000). The CPTSD, by principal component factor analysis with obliminal rotation, yields two meaningful factors, i.e., reexperiencing/ avoidance symptoms and numbness/maladaptive symptoms. The internal consistency Cronbach's $\alpha$ were $.91, .88$, and .82 , for the total scale, factor of reexperiencing/avoidance symptoms, and factor of numbness/maladaptive symptoms, respectively.

\section{Procedure}

All data were collected during the first two weeks of September 2000, right before the anniversary of the 921 Chi-Chi Earthquake. Classroom teachers were invited to assist the investigators to administer the measures. With the support of the principals and teachers, and after a passive consent procedure, all measures were given to the students in their usual classrooms. All responses were guaranteed anonymous. Chi-square analyses were performed on symptom frequencies and two-way ANOVA followed by Tukey's HSD test for post hoc group comparisons were performed to examine age and gender effects on posttraumatic symptoms.

\section{RESULTS}

\section{Extents of Posttraumatic Stress Reactions}

Overall, $13.4 \%$ of subjects were hurt during the Earthquake, $17.4 \%, 4.9 \%$, and $25.6 \%$ of subjects 
Table 1 Subject characteristics

\begin{tabular}{|c|c|c|c|c|c|c|}
\hline & \multicolumn{2}{|c|}{$\begin{array}{c}\text { Elementary Students } \\
(N=1169)\end{array}$} & \multicolumn{2}{|c|}{$\begin{array}{c}\text { Junior High Students } \\
(N=1201)\end{array}$} & \multicolumn{2}{|c|}{$\begin{array}{l}\text { Whole Sample } \\
\qquad(N=2370)\end{array}$} \\
\hline $\operatorname{Age}^{\mathrm{a}, \mathrm{b}}$ (years) & Mean & S.D. & Mean & S.D. & Mean & S.D. \\
\hline Male & 11.31 & 0.96 & 13.94 & 1.00 & 12.65 & 1.64 \\
\hline Female & 11.22 & 0.97 & 13.97 & 0.94 & 12.60 & 1.68 \\
\hline Total & 11.26 & 0.96 & 13.96 & 0.97 & 12.63 & 1.66 \\
\hline $\operatorname{Sex}^{\mathrm{c}}$ & $N$ & $\%$ & $N$ & $\%$ & $N$ & $\%$ \\
\hline Male & 607 & & 634 & & 1241 & $52.4 \%$ \\
\hline Female & 562 & & 567 & & 1129 & $47.6 \%$ \\
\hline Total & 1169 & $49.3 \%$ & 1201 & $50.7 \%$ & 2370 & $100 \%$ \\
\hline Location $^{\mathrm{d}}$ & $N$ & $\%$ & $N$ & $\%$ & $N$ & $\%$ \\
\hline Tung-Hsih Town & 533 & & 576 & & 1109 & $46.8 \%$ \\
\hline Pu-Li Town & 636 & & 625 & & 1261 & $53.2 \%$ \\
\hline & \multicolumn{2}{|c|}{$\begin{array}{c}\text { Tung-Hsih Town } \\
(N=1056)\end{array}$} & \multicolumn{2}{|c|}{$\begin{array}{c}\text { Pu-Li Town } \\
(N=1211)\end{array}$} & \multicolumn{2}{|c|}{$\begin{array}{c}\text { Whole Sample } \\
\quad(N=2267)\end{array}$} \\
\hline Ethnic Background $^{\mathrm{e}}$ & $N$ & $\%$ & $N$ & $\%$ & $N$ & $\%$ \\
\hline Horlor Taiwanese & 132 & $12.5 \%$ & 885 & $73.1 \%$ & 1017 & $44.9 \%$ \\
\hline Hakka Taiwanese & 872 & $82.6 \%$ & 139 & $11.5 \%$ & 1011 & $44.6 \%$ \\
\hline Mainlander & 14 & $1.3 \%$ & 58 & $4.8 \%$ & 72 & $3.2 \%$ \\
\hline Native Taiwanese & 27 & $2.6 \%$ & 84 & $6.9 \%$ & 111 & $4.9 \%$ \\
\hline Others & 11 & $1.0 \%$ & 45 & $3.7 \%$ & 56 & $2.5 \%$ \\
\hline
\end{tabular}

Note. ${ }^{a}$ No gender effect on age within each grade group

${ }^{\mathrm{b}}$ Significant age difference (elementary vs. junior high samples), $t=67.71, p<.001$

${ }^{\mathrm{c}}$ No gender effect on sample size within each grade group

${ }^{\mathrm{d}}$ No location effect on sample size within each grade group

${ }^{\mathrm{e}}$ Significant ethnicity $\times$ residency interaction effect after eliminating invalid data, $\chi^{2}=1160.6, p<.001$

had family member(s) hurt, family member(s) killed, and close friend(s) hurt or killed, respectively (Table 2). About $72 \%$ of subjects' houses were damaged or destroyed, and there were still 5\% currently living in container houses. Approximately $20 \%$ of subjects were separated from their families right after the event and $2.3 \%$ were still not reunited with their families. Preliminary analyses tested age effect on endorsement of objective exposure items during and after the Earthquake in order to examine the presumption that elementary and junior high school students of this study did encounter equal ordeals of injury, death, house damage, separation from family, and current dwelling conditions. As expected, adolescents have had more traumatic experiences in the past $(t=2.19, p<.05)$. Having encountered other earthquakes, fires, typhoons, or droughts $(70.6 \%)$ and being trapped in a severely damaged house during an earthquake $(36.5 \%)$ took the lead in the trauma list.

\section{Dose Effect of Earthquake Exposure on Post- traumatic Stress Reactions}

Table 3 presents means and standard deviations of PTSD total (CPTSD), reexperiencing/ avoidance symptoms, and numbness/maladaptive symptoms among various exposure indexes one year after the Chi-Chi Earthquake. With the exception of house damage and change of dwelling, all other exposure indexes carried significant effects for posttraumatic stress reactions. Total posttraumatic stress reactions followed a "dose of exposure" pattern, with the higher scores being endorsed by those who were themselves injured $(F=20.09, p<.001)$, whose family member(s) were injured or killed $(F=9.66, p<.01)$, whose close friend(s) were injured or killed $(F=16.65, p<.001)$, and who were separated from family $(F=12.12, p<$ $.001)$. The examinations on reexperiencing/ avoidance symptoms and numbness/maladaptive symptoms across various exposure levels resulted in similar patterns (all $p s<.05 \sim .001$ ).

\section{Age and Gender Effects for Posttraumatic Stress Reactions}

Overall, the most frequent reexperiencing/ avoidance symptoms reported by male/female children and adolescents were hypervigilance (55.2\%/ $55.1 \%$ and $45.3 \% / 55.8 \%$, for children and for adolescents, respectively), worry misfortune may reoccur $(31.6 \% / 34.5 \%$ and $21.6 \% / 30.1 \%)$, and psychological distress cued by related situations $(26.4 \%$ / 
Table 2 Exposure Characteristics of Subjects

\begin{tabular}{|c|c|c|c|c|c|c|c|}
\hline \multirow[b]{2}{*}{ Self being hurt? } & \multicolumn{2}{|c|}{$\begin{array}{c}\text { Elementary } \\
\text { Students } \\
(N=1169)\end{array}$} & \multicolumn{2}{|c|}{$\begin{array}{c}\text { Junior High } \\
\text { Students } \\
(N=1201)\end{array}$} & \multicolumn{2}{|c|}{$\begin{array}{c}\text { Whole } \\
\text { Sample } \\
(N=2370)\end{array}$} & \multirow{2}{*}{ Comparison $^{\mathrm{a}}$} \\
\hline & $N$ & $\%$ & $N$ & $\%$ & $N$ & $\%$ & \\
\hline No & 981 & $84.9 \%$ & 1053 & $88.2 \%$ & 2034 & $85.8 \%$ & $\chi^{2}=6.50^{\mathrm{b}}$, n.s. \\
\hline Mildly hurt, recovered & 153 & $13.2 \%$ & 131 & $11.0 \%$ & 284 & $12.0 \%$ & $\chi^{2}=1.74^{\mathrm{c}}$, n.s. \\
\hline Moderately hurt, recovering & 15 & $1.3 \%$ & 7 & $0.6 \%$ & 22 & $0.9 \%$ & \\
\hline Moderately hurt, recovered & 5 & $0.4 \%$ & 2 & $0.2 \%$ & 7 & $0.3 \%$ & \\
\hline Severely hurt, recovering & 2 & $0.2 \%$ & 1 & $0.1 \%$ & 3 & $0.1 \%$ & \\
\hline Family member(s) being hurt? & $N$ & $\%$ & $N$ & $\%$ & $N$ & $\%$ & \multirow{3}{*}{$\chi^{2}=3.63$, n.s. } \\
\hline No & 933 & $81.1 \%$ & 1001 & $84.0 \%$ & 1934 & $82.6 \%$ & \\
\hline Yes & 218 & $18.9 \%$ & 190 & $16.0 \%$ & 408 & $17.4 \%$ & \\
\hline Family member(s) being killed? & $N$ & $\%$ & $N$ & $\%$ & $N$ & $\%$ & \multirow{3}{*}{$\chi^{2}=0.40$, n.s. } \\
\hline No & 1057 & $95.4 \%$ & 1081 & $94.8 \%$ & 2138 & $95.1 \%$ & \\
\hline Yes & 51 & $4.6 \%$ & 59 & $5.2 \%$ & 110 & $4.9 \%$ & \\
\hline Close friend(s) being hurt or killed? & $N$ & $\%$ & $N$ & $\%$ & $N$ & $\%$ & \multirow{3}{*}{$\chi^{2}=1.99$, n.s. } \\
\hline No & 804 & $75.8 \%$ & 810 & $73.2 \%$ & 1649 & $74.4 \%$ & \\
\hline Yes & 257 & $24.2 \%$ & 310 & $26.8 \%$ & 567 & $25.6 \%$ & \\
\hline House being damaged or destroyed? & $N$ & $\%$ & $N$ & $\%$ & $N$ & $\%$ & \multirow{7}{*}{$\begin{array}{l}\chi^{2}=2.97^{\mathrm{d}}, \text { n.s. } \\
\chi^{2}=2.86^{\mathrm{e}}, \text { n.s. }\end{array}$} \\
\hline No damage at all & 318 & $28.8 \%$ & 305 & $26.7 \%$ & 623 & $27.7 \%$ & \\
\hline Slightly damaged, but repaired & 304 & $27.5 \%$ & 311 & $27.3 \%$ & 615 & $27.4 \%$ & \\
\hline Slightly damaged, under repairing & 57 & $5.2 \%$ & 57 & $5.0 \%$ & 114 & $5.1 \%$ & \\
\hline Partially damaged, but repaired & 196 & $17.7 \%$ & 197 & $17.3 \%$ & 393 & $17.5 \%$ & \\
\hline Partially damaged, under repairing & 55 & $5.0 \%$ & 58 & $5.1 \%$ & 113 & $5.0 \%$ & \\
\hline Totally destroyed & 175 & $15.8 \%$ & 213 & $18.7 \%$ & 388 & $17.3 \%$ & \\
\hline Separation from family? & $N$ & $\%$ & $N$ & $\%$ & $N$ & $\%$ & \multirow{4}{*}{$\chi^{2}=1.44$, n.s. } \\
\hline Never & 894 & $79.3 \%$ & 956 & $79.8 \%$ & 1850 & $\overline{79.6 \%}$ & \\
\hline Once separated, but have reunited & 203 & $18.0 \%$ & 219 & $18.3 \%$ & 422 & $18.2 \%$ & \\
\hline Still separated from family & 30 & $2.7 \%$ & 23 & $1.9 \%$ & 53 & $2.3 \%$ & \\
\hline Current dwelling? & $N$ & $\%$ & $N$ & $\%$ & $N$ & $\%$ & \multirow{5}{*}{$\begin{array}{l}\chi^{2}=11.24^{\mathrm{f}}, p<.05 \\
\chi^{2}=2.55^{\mathrm{g}}, \text { n.s. }\end{array}$} \\
\hline Original house & 881 & $80.8 \%$ & 924 & $84.8 \%$ & 1805 & $82.8 \%$ & \\
\hline Container house & 62 & $5.7 \%$ & 48 & $4.4 \%$ & 110 & $5.0 \%$ & \\
\hline Relative's house & 50 & $4.6 \%$ & 56 & $5.1 \%$ & 106 & $4.9 \%$ & \\
\hline New rental house & 98 & $9.0 \%$ & 62 & $5.7 \%$ & 160 & $7.3 \%$ & \\
\hline & Mean & S.D. & Mean & S.D. & Mean & S.D. & \multirow[b]{2}{*}{$t=2.19, p<.05$} \\
\hline No. of past traumatic experience(s) & 2.04 & 1.90 & 2.20 & 1.60 & 2.12 & 1.75 & \\
\hline
\end{tabular}

$31.8 \%$ and $19.7 \% / 29.8 \%$ ). In the numbness/maladaptive symptom cluster, sleep problems $(21.8 \%$ and $18.8 \%$, for male and female, respectively), memory impairment $(21.2 \%$ and $16.8 \%)$, restricted negative affects $(21.2 \%$ and $16.6 \%)$, and difficulty concentrating $(19.7 \%$ and $17.6 \%)$ were most frequent in elementary school children. Difficulty concentrating (18.6\% and $19.3 \%$, for male and for female, respectively), memory impairment $(17.2 \%$ and $13.0 \%)$, sleep problems $(12.4 \%$ and $14.8 \%)$, and restricted negative affects $(14.5 \%$ and $10.6 \%)$ took the lead in the list of junior high school adolescents. Age differences of endorsement frequencies between children and adolescents were noted in some reexperiencing/avoidance symptoms and most numbness/maladaptive symptoms at significant levels of $p s<.05 \sim .001$ as shown in Table 4. Gender differences of symptom endorsement were noted in intrusion and sense of foreshortened future for children as well as in hypervigilance, worry misfortune may reoccur, psychological distress cued by 
Table 3 Exposure Effects on PTSD

\begin{tabular}{|c|c|c|c|c|c|c|c|c|c|}
\hline & \multicolumn{3}{|c|}{ PTSD } & \multicolumn{3}{|c|}{$\begin{array}{c}\text { Reexperience/ } \\
\text { Avoidance }\end{array}$} & \multicolumn{3}{|c|}{$\begin{array}{c}\text { Numbness/ } \\
\text { Maladaptive }\end{array}$} \\
\hline & Mean & S.D. & $F$ & Mean & S.D. & $F$ & Mean & S.D. & $F$ \\
\hline \multicolumn{10}{|l|}{ Injury to Self } \\
\hline No & 25.90 & 15.01 & $20.09 * * *$ & 16.56 & 9.32 & $19.52 * * *$ & 9.37 & 6.90 & $14.56 * * *$ \\
\hline Yes & 30.20 & 13.41 & & 20.40 & 8.90 & & 9.80 & 7.05 & \\
\hline \multicolumn{10}{|l|}{$\begin{array}{l}\text { Injuries or deaths of family } \\
\text { member(s) }\end{array}$} \\
\hline No & 24.43 & 14.59 & $9.66 * *$ & 16.24 & 9.02 & $10.29 * * *$ & 9.21 & 6.80 & $5.73 *$ \\
\hline Yes & 27.80 & 16.30 & & 17.76 & 10.21 & & 10.06 & 7.24 & \\
\hline \multicolumn{10}{|l|}{$\begin{array}{l}\text { Injuries or deaths of close } \\
\text { friend(s) }\end{array}$} \\
\hline No & 25.05 & 14.79 & $16.65 * * *$ & 16.05 & 9.22 & $17.68 * * *$ & 9.00 & 6.75 & $11.81 * *$ \\
\hline Yes & 28.05 & 15.21 & & 17.97 & 9.45 & & 10.17 & 7.04 & \\
\hline \multicolumn{10}{|l|}{ House damages } \\
\hline No damage at all & 24.80 & 14.93 & 1.26 & 15.77 & 9.35 & $4.46 * *$ & 9.05 & 6.82 & 1.20 \\
\hline Slightly damaged & 25.48 & 14.71 & & 16.22 & 8.93 & & 9.31 & 6.91 & \\
\hline Partially damaged & 27.44 & 14.76 & & 17.70 & 9.40 & & 9.74 & 6.71 & \\
\hline Totally destroyed & 26.50 & 15.77 & & 17.00 & 9.70 & & 9.52 & 7.22 & \\
\hline \multicolumn{10}{|l|}{ Changes of dwelling } \\
\hline Original house & 25.76 & 14.78 & 0.73 & 16.47 & 9.20 & 0.56 & 9.32 & 6.83 & 0.84 \\
\hline Container house & 27.98 & 16.60 & & 17.66 & 10.25 & & 10.42 & 7.51 & \\
\hline Relative's house & 25.98 & 15.23 & & 16.66 & 9.46 & & 9.32 & 6.73 & \\
\hline Newly rental house & 25.91 & 16.36 & & 16.42 & 9.85 & & 8.81 & 6.73 & \\
\hline \multicolumn{10}{|l|}{ Separation from family } \\
\hline Never & 25.04 & 14.75 & $12.12 * * *$ & 16.08 & 9.24 & $10.20 * * *$ & 8.99 & 6.70 & $10.39 * * *$ \\
\hline $\begin{array}{l}\text { Once separated, but } \\
\text { have reunited }\end{array}$ & 28.20 & 14.98 & & 17.88 & 9.17 & & 10.34 & 9.15 & \\
\hline Still separated from family & 31.94 & 17.55 & & 20.06 & 10.75 & & 11.88 & 8.03 & \\
\hline
\end{tabular}

related situations, exaggerated startle responses, restricted negative affects, and guilty feeling for adolescents. Means and standard deviations for PTSD total and subscales by age and gender groups as well as the summary of ANOVA results are presented in Table 5. The PTSD total showed significant main effects for age $(F=16.42, p<.001)$ and gender $(F=$ $5.23, p<.05)$, and their interaction age $(F=5.07, p<$ $.05)$. The reexperiencing/ avoidance subscale showed significant main effects for age $(F=16.99, p<.001)$ and gender $(F=19.60, p<.001)$, and the numbness/ maladaptive subscale yielded a significant main effect for age $(F=14.62, p<.001)$ and age by gender interaction effect $(F=4.01, p<.05)$. Further post hoc comparisons indicated that younger children presented not only more reexperiencing/avoidance symptoms, but also more numbness/maladaptive symptoms. With regard to numbness/maladaptive symptoms, boys reported more, while male adolescents presented fewer than their female counterparts. Moreover, as indicated in Table 5, examination of the ANOV As for each symptom item revealed significant main effects and/or interaction effect on several symptoms.

\section{DISCUSSION}

Little information exists concerning the chronic posttraumatic reactions among children and adolescents in Taiwan after the Chi-Chi Earthquake. Extant local studies mainly reported short-term (i.e., three to four months) posttraumatic symptoms and used rather restricted samples from only one school or one town. No direct comparison between youths at various developmental stages, i.e., elementary school children and junior high school adolescents, were reported. By using more representative samples from two harshly impacted townships and assessing the subjects within two weeks prior to the anniversary of the Earthquake, this study reports that there are still a large number of children and adolescents reporting symptoms from the reexperiencing/avoidance cluster of PTSD one year after the Chi-Chi Earthquake. Especially, anxiety- prone symptoms like hypervigilance and worry misfortune may reoccur were present in no less than one third of the subjects. Although the study did not intend to, nor was it able to, define PTSD using DSM-IV diagnostic criteria for youths, the aforementioned symptoms 
Table 4 Symptom Endorsement Frequencies One Year after the Chi-Chi Earthquake

\begin{tabular}{|c|c|c|c|c|c|c|c|}
\hline & \multicolumn{3}{|c|}{ Elementary Students } & \multicolumn{3}{|c|}{ Junior High Students } & \multirow{2}{*}{$\begin{array}{c}\text { Elementary vs. } \\
\text { Junior High } \\
\chi^{2} \\
\end{array}$} \\
\hline & male & female & $\chi^{2}$ & male & female & $\chi^{2}$ & \\
\hline hypervigilance & 55.2 & 55.1 & 0.00 & 45.3 & 55.8 & $12.48 * *$ & $4.97 *$ \\
\hline worry misfortune may reoccur & 31.6 & 34.5 & 1.03 & 21.6 & 30.1 & $10.57 * *$ & $13.98 * * *$ \\
\hline cues/psychological distress & 26.4 & 31.8 & 3.74 & 19.7 & 29.8 & $15.69 * *$ & $5.90 *$ \\
\hline avoidance of trauma-related thoughts & 20.9 & 25.9 & 3.68 & 21.6 & 23.2 & 0.46 & 0.30 \\
\hline intrusive images, sounds, and thoughts & 24.4 & 30.5 & $5.02 *$ & 18.2 & 22.6 & 3.35 & $14.97 * * *$ \\
\hline exaggerated startle responses & 20.4 & 24.1 & 2.15 & 15.5 & 23.7 & $12.10 * *$ & 2.92 \\
\hline Irritability and anger & 22.3 & 18.4 & 2.46 & 18.0 & 17.9 & 0.00 & 2.03 \\
\hline avoiding activities, places, and people & 22.7 & 21.6 & 0.18 & 13.9 & 17.6 & 2.84 & $15.50 * * *$ \\
\hline cues/physiological reactions & 14.5 & 17.1 & 1.29 & 13.2 & 16.1 & 1.92 & 0.70 \\
\hline sense of reliving the experiences & 24.9 & 23.3 & 0.36 & 14.0 & 12.5 & 0.52 & $42.46 * * *$ \\
\hline recurrent distressing dreams & 23.2 & 19.7 & 2.03 & 11.6 & 11.4 & 0.02 & $40.48 * * *$ \\
\hline difficulty concentrating & 19.7 & 17.6 & 0.75 & 18.6 & 19.3 & 0.07 & 0.06 \\
\hline memory impairment & 21.2 & 16.8 & 3.33 & 17.2 & 13.0 & 3.79 & $5.23 *$ \\
\hline insomnia and difficulty falling asleep & 21.8 & 18.8 & 1.54 & 12.4 & 14.8 & 1.31 & $18.21 * * *$ \\
\hline restricted negative affect & 21.2 & 16.6 & 3.69 & 14.5 & 10.6 & $3.90 *$ & $16.63 * * *$ \\
\hline guilty feeling & 17.9 & 14.9 & 1.76 & 13.6 & 9.0 & $5.76^{*}$ & $11.52 * *$ \\
\hline restricted positive affect & 16.4 & 14.7 & 0.56 & 10.6 & 9.4 & 0.42 & $14.44 * * *$ \\
\hline sense of foreshortened future & 16.9 & 11.5 & $6.29 *$ & 8.9 & 10.7 & 1.04 & $10.90 * *$ \\
\hline detachment from others & 11.6 & 9.4 & 1.36 & 7.2 & 6.1 & 0.56 & $10.79 * *$ \\
\hline diminished interest in significant activities & 11.4 & 9.9 & 0.63 & 7.5 & 5.0 & 3.01 & $13.75 * * *$ \\
\hline
\end{tabular}

$* p<.05 * * p<.01 * * * p<.001$

appear to be more trauma-specific and may lead to future PTSD diagnosis, if sustained.

Consistent with previous studies (Chao and $\mathrm{Wu}$ 2000; Lonigan et al., 1994; McFarlane 1987; Shore et al., 1986; Pynoos et al., 1996), severity of posttraumatic stress reactions was also found to carry a "dose effect" of earthquake exposure in this study. For children and adolescents, index for deaths or injuries (including injuries to self, deaths or injuries of family members, and deaths or injuries of close friends) and index for life destruction (i.e., separation from family) appeared more essential than other exposure indexes such as property loss. It is noteworthy that, among various exposure indexes, the index for deaths or injuries seems to be more emotionloaded and relation-oriented. The transition from late childhood to early adolescence is assumed to be a period of refinement of concepts about self and world as well as changes in parent-child and peer relationships rather than generation of properties, a developmental task often seen in adulthood (Erikson, 1968). Traumatization at these stages is often considered to cause a breaching of emotional consolidation in developmental drift. Loss of complete relationships due to injuries or deaths in others as well as disruption of a belief in a socially modulated world with unavoidable dangers due to injuries in self may lead to "existential dilemma" over the conflict between the unprotected past and the uncertain future. Existential anxiety may then breed neurotic anxiety and fear as often seen in PTSD. Unsolved in this study, however, is whether the grief process may be a mediator for such a dose effect of emotion-modulated exposure.

Furthermore, existing literature is not yet conclusive about age and gender effects on the vulnerability of children and adolescents following a traumatic event. Variation in the prevalence of PTSD symptoms was found across age and gender groups in this study. Younger children and females were more likely to report PTSD symptoms overall, and more females and younger children reported symptoms within re-experiencing and avoidance clusters of the PTSD diagnostic criteria of DSM-IV. More male adolescents than boys endorsed symptoms of restricted negative affects, sense of guilt, and hopelessness, whereas the boys who endorsed these symptoms tended to present such symptoms in a more extreme way. The pattern could be accounted for by the portrait of "universal adolescents" resulted from a cross-country study (Offer, Ostrov, Howard, Atkinson, 1988; cited from Atwater, 1992) that male adolescents tend to report better control of their feelings. On the other hand, it has been speculated that younger children seem to lack adequate defenses and resources against threat and loss, so they develop more posttraumatic symptoms (Shannon et al., 1994). As a result, although being younger and/or female may be high risk for anxiety-tone symptoms in general and PTSD symptoms in specific, being older and male may result in more psychosomatic and 
Table 5 Summary of ANOVA Results of PTSD Symptoms by Age and Gender

\begin{tabular}{|c|c|c|c|c|c|c|c|c|c|}
\hline & \multicolumn{4}{|c|}{ Elementary Students } & \multicolumn{4}{|c|}{ Junior High Students } & \multirow{3}{*}{$\begin{array}{c}\text { ANOVA } \\
\text { Results and } \\
\text { Significant } \\
\text { levels }\end{array}$} \\
\hline & \multicolumn{2}{|c|}{ male } & \multicolumn{2}{|c|}{ female } & \multicolumn{2}{|c|}{ male } & \multicolumn{2}{|c|}{ female } & \\
\hline & Mean & S.D. & Mean & S.D. & Mean & S.D. & Mean & S.D. & \\
\hline PTSD & 27.25 & 15.77 & 27.27 & 15.07 & 23.07 & 14.84 & 26.08 & 13.71 & $A^{* * *}, S^{*}, A \times S^{*}$ \\
\hline reexperier & 16.92 & 9.40 & 18.10 & 9.59 & 14.63 & 9.06 & 17.05 & 8.95 & $\mathrm{~A}^{* * *}$ \\
\hline numbne & 11.02 & 7.53 & 10.33 & 7.04 & 9.26 & 7.53 & 078 & 6.18 & $\mathrm{~A}^{* * *}, \mathrm{~A} \times \mathrm{S}^{*}$ \\
\hline \multicolumn{10}{|l|}{ Reexperiencing/Avoidance Symptoms } \\
\hline hypervigilance & 2.60 & 1.35 & 2.62 & 1.27 & 2.35 & 1.27 & 2.67 & 1.13 & $\mathrm{~S}^{* *}, \mathrm{~A} \times \mathrm{S}^{* *}$ \\
\hline worry misfortune $n$ & 1.72 & 1.51 & 1.91 & 1.47 & 1.44 & 1.36 & 1.86 & $1.33 \mathrm{~A}$ & $A^{* *}, S^{* * *}, A \times s$ \\
\hline cues/psychological dist & 1.64 & 1.3 & 1.93 & 1.29 & 1.48 & 1.20 & 1.67 & 1.23 & $A^{*}, S^{* * *}$ \\
\hline avoidance of trauma-related thoughts & 1.42 & 1.36 & 1.61 & 1.39 & 1.41 & 1.34 & 1.48 & 1.37 & $\mathrm{~S}^{*}$ \\
\hline intrusive images, sounds, $\&$ thoughts & 1.57 & 1.38 & 1.80 & 1.39 & 1.33 & 1.21 & 1.56 & 1.26 & $A^{* * *}, S^{* * *}$ \\
\hline exaggerated startle responses & 1.29 & 1.33 & 1.51 & 1.34 & 1.12 & 1.21 & 1.54 & 1.29 & $S^{* * *}$ \\
\hline Irrit & 1.54 & 1.30 & 1.44 & 1.22 & 1.47 & 1.18 & 1.47 & 1.16 & n.s. \\
\hline avoidi & 1.42 & 1.37 & 1.41 & 1.31 & 1.17 & 1.21 & 1.31 & 1.26 & $A^{* *}$ \\
\hline cues/physiological reaction & 1.00 & 1.23 & 1.07 & 1.33 & 0.94 & 1.24 & 1.16 & 1.28 & $\mathrm{~S}^{* *}$ \\
\hline sense of reliving the & 1.49 & 1.39 & 1.50 & 1.37 & 1.11 & 1.20 & 1.09 & 1.14 & $A^{* * * *}$ \\
\hline recurrent distressing dreams & 1.45 & 1.36 & 1.41 & 1.33 & 1.02 & 1.15 & 1.01 & 1.11 & $\mathrm{~A}^{* * *}$ \\
\hline \multicolumn{10}{|l|}{ Numbness/Maladaptive Symptoms } \\
\hline difficulty co & 1.35 & 1.33 & 1.28 & 1.29 & .36 & 1.27 & 1.44 & 1.16 & n.s \\
\hline mem & 1.32 & 1.38 & 1.29 & 1.29 & 1.23 & 1.28 & 1.18 & 1.14 & \\
\hline and difficulty falling & 1.37 & 1.38 & 1.3 & 1.31 & 0.95 & 1.19 & 1.18 & 1.19 & $\mathrm{~A}^{* * *}, \mathrm{~A} \times \mathrm{S}^{* * *}$ \\
\hline ative affect & 1.42 & 1.36 & 1.29 & 1.27 & 1.17 & 1.20 & 1.10 & 1.08 & $A^{* * *}$ \\
\hline guilty feeling & 1.23 & 1.30 & 1.08 & 1.24 & 0.99 & 1.20 & 0.92 & 1.11 & $A^{* * *}, S^{*}$ \\
\hline restricted positive affect & 1.06 & 1.28 & 1.00 & 1.25 & 0.87 & 1.14 & 0.89 & 1.07 & $\mathrm{~A}^{* *}$ \\
\hline sense of foreshort & 0.95 & 1.33 & 0.84 & 1.22 & 0.72 & 1.13 & 0.92 & 1.14 & \\
\hline detachment from o & 0.86 & 1.16 & 0.82 & 1.13 & 0.62 & 1.00 & 0.71 & 0.98 & $A^{* * * *}$ \\
\hline $\begin{array}{l}\text { diminished interest in significant } \\
\text { activities }\end{array}$ & 0.81 & 1.17 & 0.76 & 1.01 & 0.69 & 1.02 & 0.70 & 0.94 & $*$ \\
\hline
\end{tabular}

Note. S: Significant gender effect; A: Significant age effect; A $\times$ S: Significant age $\times$ gender interaction effect; n.s.: Non-significant ${ }^{* * *} p<.001,{ }^{* *} p<.01,{ }^{*} p<.05$

acting-out symptoms in the future.

Although existing data show that most people who are exposed to dreadful experiences survive without developing psychiatric disorders, an undeniable portion of younger survivors of traumatic events do develop PTSD (Breaslau et al., 1995). According to the hypothetical conception of developmental arrest, i.e., a condition wherein the index person fixes at the developmental stage during which $\mathrm{s} / \mathrm{he}$ had been traumatized, any traumatization during childhood or adolescence may transform into psychological disorders like conduct disorder, depression, and psychosomatic symptoms and may lead to certain complications later on in life (Herman, 1992). Indeed, it has been postulated, in the very beginning, that the relationship of age/developmental level with the extent of PTSD symptoms following a trauma may not be as simple and straightforward as it appears. For instance, Bensheim (1960, cited by Maercker, 1999) assumed that "traumatization during childhood would lead to changes in psychomotor functioning in later life such as chronic urge to move, hysterical movement disorders as well as anxiety attacks, and antisocial behavior. Traumatization during adolescence was assumed to lead to psychovegetative problems, e.g., heart neurosis, psychosomatic illnesses." Before this speculation can be examined perhaps 10 years later, and before necessary prevention and intervention remedies are implemented, it will be essential to inspect the specific effects of developmental level on posttraumatic reactions in the earthquake-affected children and adolescents. Indeed, the present study is the first step of a longitudinal series of prospective research studies by the authors. Hence, the findings of the present study may provide a database for future studies and a more in-depth understanding of the link between childhood trauma and future psychopathology could be attained accordingly.

The inconsistencies of findings may arise from diverse natures and levels of disaster exposure, the age of the children exposed to the disaster, variations in diagnostic criteria and instruments, various 
assessment time periods elapsed from disaster occurrence, and ethnocultural differences of samples (Friedman and Marsella, 1996; Koral, et al., 1999; March et al., 1997; McFarlane, 1987). The disparities of findings from previous studies may reflect methodological differences. Comparisons with other local studies are limited by various assessment times elapsed from the Earthquake, various degrees of sample representa-tiveness, and various in-struments.

Nevertheless, the present study resulted in similar chronic symptom patterns found by Bradbaun (1991) and Green et al. (1991). Bradbaun (1991) found that recollection of the earthquake caused by reminders, feeling fearful while recollecting the event, exaggerated startle responses, and intrusive thoughts were most frequent in children of 10-12 years old 68 months after the San Francisco Earthquake. Green, et al. (1991) found that the most frequently reported symptoms in children two years after the Buffalo Creek flooding disaster included painful feelings caused by reminders, diminished social activities, and restricted affects. The present study found that hypervigilance, worry misfortune may reoccur, psychological distress cued by related situations, and sleep problems were most frequent in elementary school children one year after the Chi-Chi Earthquake. Findings of the present study are limited in several ways.

First, those whose households were more damaged may have already moved to other cities, so, were not available for the sample. Second, while the present findings can be strengthened by a populationbased sampling strategy, ability to generalize suffers because of lacking a non-exposure sample recruited from a non-affected area in the data set. As pointed out by Pynoos et al. (1996), systematic community and population-based studies will allow for more rigorous investigation of factors that predict or mediate the severity and course of posttraumatic reactions among children and adolescents. Further follow-up research, if plausible, should include a non-exposure sample in order to examine the dose effect along a broader spectrum of trauma exposure.

Finally, of scientific interest, the increasing research on childhood trauma and its consequences, both positive and negative ones, will contribute to a better understanding of the interplay of trauma and human sufferings/revitalizations. Of humanistic concern, the relatively higher vulnerability of children and adolescents calls professional attention to early detection and prevention. Given that age and gender show variable effects on developing post-traumatic symptoms, it may suggest a need to implement a broad disaster recovery project with periodic screenings as well as age-specific and gender-appropriate mental health programs.

\section{ACKNOWLEDGEMENTS}

The research reported in this paper was jointly supported by grants from the National Center for Research on Earthquake Engineering, Taipei, Taiwan, R.O.C. [NCREE-00-061] and the National Science Council [NSC-90-2625-Z-002-034 and NSC-90-2625 -Z-002-033]. The authors wish to express their deep appreciation to Mr. C. C. Hsu of the National Center for Research on Earthquake Engineering for his assistance and information. The authors would also like to acknowledge that many earthquake survivors and principals and teachers of several elementary and junior high schools in earthquake epicenter in Taiwan have provided us their substantial participation and help with data collection. All these made the study possible.

\section{REFERENCES}

1. American Psychiatric Association, 1980, Diagnostic and Statistical Manual of Mental Disorders, 3rd edition (DSM-III), American Psychiatric Association, Washington, DC, USA.

2. American Psychiatric Association, 1987, Diagnostic and Statistical Manual of Mental Disorders, 3rd edition-revised (DSM-III-R), American Psychiatric Association, Washington, DC, USA.

3. Atwater, E., 1992, Adolescence, Prentice Hall Inc., New Jersey, USA.

4. Belter, R. W., Dunn, S. E., and Jeney, P., 1991, "The psychological Impact of Hurricane Hugo on Children: A Needs Assessment," Advances in Behavior Research Therapy, 13, pp. 155-161.

5. Blom, G. E., 1984, "A School Disaster-intervention and Research Aspects," Journal of the American Academy of Child Psychiatry, Vol. 25, No. 3, pp. 336-345.

6. Bradburn, I. S., 1991, "After the Earth Shook: Children's Stress Symptoms 6-8 Months After a Disaster," Advances in Behavior Research Therapy, Vol. 13, pp. 173-179.

7. Breslau, N., Davis, G. C., and Andreski, P., 1995, "Risk Factors for PTSD-related Traumatic Events: A Prospective Analysis," American Journal of Psychiatry, Vol. 152, No. 4, pp. 529-535.

8. Chao, C. C., and Wu, Y. Y., 2000, "Preliminary Report of Post-traumatic Stress Reactions in Child Survivors After the Chi-Chi Earthquake," Proceedings of International Workshop on Annual Commemoration of Chi-Chi Earthquake, Loh, C. H., and Liao, W. I., (ed.), Vol. IV-Social Aspect, pp. 270-282.

9. Chen, S. H., Hung, F. C., Lin, Y. S., and Tseng, H. M., 2000, "Lessons from the 921 Earthquake: 
Trauma, Psychosocial Reactions, and Psychological Growth," Proceedings of International Workshop on Annual Commemoration of Chi-Chi Earthquake, C. H., Loh, and W. I., Liao, (ed.), Vol. IV-Social Aspect, pp. 318-331.

10. Chen, S. H., Hung, F. C., Lin, Y. S., and Tseng, H. M. 2002, "Trauma and Psychosocial Aftermath among High- and Low-Exposure Adults Three Months post the 921 Chi-Chi Earthquake in Taiwan," Chinese Journal of Psychology, Vol. 44, No. 2, pp. 167-188.

11. Chen, S. H., Lin, Y. S., Hung, F. C., and Tseng, H. M., 2000, "Posttraumatic Psychosocial Reactions After the 921 Earthquake in Taiwan: Psycho-socio- cultural Connotation of the Changed and Unchanged," Journal of Culture and Society, Vol. 10, pp. 35-60 (in Chinese).

12. Cheng, J. J., Tan, H., Chen, C. Y., Tung, P. L., and Wang, S., 2000, "Estimation of Psychological Impact After the 921 Earthquake in Nantao Area," Proceedings of International Workshop on Annual Commemoration of Chi-Chi Earthquake, Loh, C. H., and Liao, W. I., (ed.), Vol. IV-Social Aspect, pp. 299-307.

13. Erikson, E. H., 1968, Identity, Youth, and Crisis. Norton, New York, NY, USA.

14. Friedman, M. J. and Marsella, A. J., 1996, "Posttraumatic Stress Disorder: An Overview of the Concept," Ethnocultural Aspects of Posttraumatic Stress Disorder: Issues, Research, and Clinical Applications, Marsella, A. J., Friedman, M. J., Gerrity, E. T., and R. M., Scurfield ed., American Psychological Association, Washington, DC, USA, pp.11-32.

15. Green, B. L., 1991, "Evaluating the Effects of Disasters," Journal of Consulting and Clinical Psychology, Vol. 59, pp. 538-546.

16. Green, B. L., Grace, M., Vary, M. G., Kramer, T., Gleser, G. C., and Leonard, A. C., 1994, "Children of Disaster in the Second Decade: A 17 Year Follow-up of Buffalo Creek Survivors," Journal of American Academy of Child and Adolescent Psychiatry, Vol. 33, No. 1, pp. 71-79.

17. Green, B. L., Korol, M., Grace, M. C., Vary, M. G., Leonard, A. C., Gleser, G. C., and Cohen, S. S., 1991, "Children and Disaster: Age, Gender, and Parental Effects on PTSD Symptoms," Journal of American Academy of Child and Adolescent Psychiatry, Vol. 30, No. 6, pp. 945-951.

18. Herman, J. L., 1992, Trauma and Recovery, Basic Books, New York, NY, USA.

19. Hsu, W. Y., 2000, "Coping Styles and Psychological Symptoms in Students from 921 Earthquake," Proceedings of International Workshop on Annual Commemoration of Chi-Chi Earthquake, C. H. Loh and W. I. Liao, ed., Vol.
IV-Social Aspect, pp. 256-269 (in Chinese).

20. International Federation of the Red Cross and the Red Crescent Societies, 1993, Word Disaster Report 1993. Dordrecht, Martinus Nijhoff, The Netherlands.

21. Kessler, R. C., Sonnega, A., Bromet, E., Hughes, M., and Nelson, C. B., 1995, "Posttraumatic Stress Disorder in the National Comorbidity Survey," Archives of General Psychiatry, Vol. 52, No. 12, pp. 1048-1060.

22. Koral, M., Green, B. L., and Gleser, G. C., 1999, “Children's Responses to a Nuclear Waste Disaster: PTSD Symptoms and Outcome Prediction," Journal of American Academy of Child and Adolescent Psychiatry, Vol. 38, No. 4, pp. 368-375.

23. La Greca, A. M., Vernberg, E. M., Silverman, W. L., and Prinstein, M. J., 1996, "Symptoms of Posttraumatic Stress in Children After Hurricane Andrew: A Prospective Study," Journal of Consulting and Clinical Psychology, Vol. 64, pp. 712723.

24. Lin, Y. H., 2001, "Posttraumatic Stress Reaction of Adolescents After the Chi-Chi Earthquake: Gender and Exposure Effect Analysis," Master Thesis, National Taiwan University, Taipei, Taiwan.

25. Lin, Y. S., Chen, S. H., Hung, F. C., and Tseng, H. M., 2001, "Different Voices: Exploring the Disastrous Reactions and Adaptations between Female and Male," Proceedings of International Workshop on Annual Commemoration of Chi-Chi Earthquake, Loh, C. H., and Liao, W. I., ed., Vol. IV-Social Aspect, pp. 399-423 (in Chinese).

26. Lonigan, C. J., Shannon, M. P., Taylor, C. M., Finch, A. J., and Sallee, F. R., 1994, "Children Exposed to Disaster, II: Risk Factors for the Development of Posttraumatic Symptomatology," Journal of American Academy of Child and Adolescent Psychiatry, Vol. 33, pp. 94-105.

27. Maercker, A., 1999, "Lifespan Psychological Aspects of Trauma and PTSD: Symptoms and Psychosocial Impairments," Post-Traumatic Stress Disorder: A Lifespan Developmental Perspective, Maercker, A., Schützwohl, M., and Solomon, Z., eds., Hogrefe and Huber Publishers, Seattle, WA, USA, pp.7-41.

28. March, J. S., Amaya-Jackson, L., Terry, R., and Costanzo, P., 1997, "Posttraumatic Symptomatology in Children and Adolescents after an Industrial Fire," Journal of American Academy of Child and Adolescent Psychiatry, Vol. 36, pp. 1080-1088.

29. McFarlane, A. C., 1987, "Posttraumatic Phenomena in a Longitudinal Study of Children Following a Natural Disaster," Journal of American 
Academy of Child and Adolescent Psychiatry, Vol. 26, pp. 764-749.

30. Nader, K., Pynoos, R., Fairbanks, L., Frederick, C., 1990, "Children's PTSD Reactions One Year After a Sniper Attack at Their School," American Journal of Psychiatry, Vol. 147, No. 11, pp. 1526-1530.

31. National Alliance for Post-Earthquake Reconstruction, 2000, "Q and A: Post 921 Earthquake Reconstruction/Q and A: Post-921 Rehabilitation 1," Taipei, Taiwan.

32. Norris, F., 1992, "Epidemiology of Trauma: Frequency and Impact of Different Potentially Traumatic Events on Different Demographic Groups," Journal of Consulting and Clinical Psychology, Vol. 60, pp. 409-418.

33. Orlee, U., 1993, "Annotation: Children's Reaction to Traumatic Event," Journal of child Psychology and Psychiatry, Vol. 34, No. 2, pp. 115127.

34. Pynoos, R. S., Goenjian, A., and Tashjian, M. et al., 1993, "Posttraumatic Stress Reactions in Children After the 1988 Armenian Earthquake," British Journal of Psychiatry, Vol. 163, pp. 239-247.

35. Pynoos, R. S., Steinberg, A. M., Geonjian, A., 1996, "Traumatic Stress in Children and Adolescence Recent Developments and Current Controversies," Traumatic Stress: The Effects of Overwhelming Experience on Mind, Body, and Society, B. A. van der Kolk, A. C. Mcfarlane, and L. Weisaeth ed., The Guilford Press, New York, NY, USA, pp. 331-358.

36. Shannon, M. P., Lonigan, C. J., Finch, A. J., and
Taylor, C. M., 1994, "Children Exposed to Disaster: I. Epidemiology of PTSD-traumatic Symptoms and Symptom Profiles," Journal of American Academy of Child and Adolescent Psychiatry, Vol. 33, No. 1, pp. 80-92.

37. Shaw, J. A., Applegate, B., Schorr C., 1996, "Twenty-one-month Follow-up Study of Schoolage Children Exposed to Hurricane Andrew," Journal of American Academy of Child and Adolescent Psychiatry, Vol. 35, No. 3, pp. 359-364.

38. Shore, J. H., Tatum, E. L., and Vollmer, W. M., 1986, "Psychiatric Reactions to Disaster: The Mount St. Helens Experience," American Journal of Psychiatry, Vol. 143, pp. 590-595.

39. Soong, W. T., Lee, Y. C., Huang, R. R., Liu, Y. S., Yu, W. C., and Chen, Y. S., 2000, "A Comparative Study of Post-traumatic Symptoms between Students Living at $\mathrm{Yu}$-Chih and Relocation to Kaohsiung After the Chi-Chi Earthquake," Proceedings of International Workshop on Annual Commemoration of Chi-Chi Earthquake, Loh, C. H., and Liao, W. I., ed., Vol. IVSocial Aspect, pp. 308-317.

40. Wu, Y. C., Chen, S. H., and Tseng, H. M., 2000, Survey of Posttraumatic Reactions and Copings After the 921 Earthquake, National Center for Research on Earthquake Engineering, Taipei, Taiwan [NCREE-00-061] (in Chinese).

Manuscript Received: Aug. 01, 2001

Revision Received: Jan. 28, 2002 and Accepted: Feb. 18, 2002

\title{
兒童青少年之地震創傷後心理症狀： 集集大地震週年研究
}

\author{
陳淑惠 ${ }^{1} \quad$ 林怡慧 $^{1}$ 曾旭民 ${ }^{2}$ 吳英璋 ${ }^{1}$ \\ ${ }^{1}$ 國立台灣大學心理學系 \\ 2 私立長庚大學醫務管理學系
}

\begin{abstract}
摘 要
本研究的目的旨在瞭解九二一地震週年後, 重建區兒童與青少年之長期性 創傷後心理症狀之呈現趨勢, 並試圖檢驗創傷暴露之劑量效果、發展階段 (年 齡)、與性別等變項對創傷後心理症狀之影響。本研究選取東勢及埔里兩區的 1169 名兒童與 1201 名青少年爲受試, 以地震損傷問卷與 PTSD 症狀指標爲工 具, 研究結果顯示 : 創傷暴露程度對長期性心理症狀具有劑量效果; 發展階段 與性別對不同的心理症狀群之出現率與嚴重度具有不同的影響力。最後, 本研 究指出定期性、系統性研究之必要, 並建議創傷後心理復健計畫應以揭顯性別 與發展階段之殊性爲依歸。
\end{abstract}

關鍵詞 : 創傷後心理症狀, 地震, 創傷暴露之劑量效果, 兒童與青少年。 